\title{
The longitudinal association between external locus of control, social cognition and adolescent psychopathology
}

\author{
Sarah A. Sullivan ${ }^{1,5}$ - Andy Thompson ${ }^{2} \cdot$ Daphne Kounali $^{1} \cdot$ Glyn Lewis $^{3}$ • \\ Stan Zammit ${ }^{1,4}$
}

Received: 24 May 2016 / Accepted: 25 January 2017 / Published online: 7 March 2017

(C) The Author(s) 2017. This article is published with open access at Springerlink.com

\begin{abstract}
Purpose To investigate the longitudinal associations between social cognitive ability an external locus of control (externality) and adolescent psychopathology.

Methods 7058 participants from a prospective population-based cohort provided data on externality, social communication, and emotion perception between 7 and 16 years and psychotic experiences and depressive symptoms at 12 and 18 years. Bivariate probit modelling was used to investigate associations between these risk factors and psychopathological outcomes.

Results Externality was associated with psychopathology at 12 (psychotic experiences OR 1.23 95\% CI 1.14, 1.33; depression OR $1.1295 \%$ CI 1.02, 1.22) and 18 years (psychotic experiences OR 1.38 95\% CI 1.23, 1.55; depression
\end{abstract}

The work for this study was carried out at the Centre for Academic Mental Health, University of Bristol.

Electronic supplementary material The online version of this article (doi:10.1007/s00127-017-1359-z) contains supplementary material, which is available to authorized users.

Sarah A. Sullivan

sarah.sullivan@bristol.ac.uk

Andy Thompson

Andrew.D.Thompson@warwick.ac.uk

Daphne Kounali

daphne.kounali@bristol.ac.uk

Glyn Lewis

Glyn.Lewis@ucl.ac.uk

Stan Zammit

stan.zammit@bristol.ac.uk; zammits@ cardiff.ac.uk

1 Centre for Academic Mental Health, University of Bristol, Oakfield House, Oakfield Grove, Clifton, Bristol BS8 2BN, UK
OR 1.40 95\% CI 1.28, 1.52). Poor social communication was associated with depression at both ages (12 years OR 1.22 95\% CI 1.11, 1.34; 18 years OR $1.2195 \%$ CI 1.10 , 1.33 ) and marginally associated with psychotic experiences. There was marginal evidence of a larger association between externality and psychotic experiences at 12 years $(p=0.06)$ and between social communication and depression at 12 years $(p=0.03)$.

Conclusions Externality was more strongly associated with psychotic experiences. At 18 years change in externality, between 8 and 16 years were associated with a larger increase in the risk of depression. Poor social communication was more strongly associated with depression.

Keywords Psychotic experiences $\cdot$ Depressive symptoms $\cdot$ Social communication $\cdot$ ALSPAC

2 Division of Mental Health and Wellbeing, Warwick Medical School, University of Warwick, Coventry CV4 7AL, UK

3 Division of Psychiatry, University College London, Charles Bell House, 67-73 Riding House Street, London W1W 7EJ, UK

4 Institute of Psychological Medicine and Clinical Neurosciences, University of Cardiff, Cardiff University School of Medicine, Haydn Ellis Building, Maindy Road, Cardiff CF24 4HQ, UK

5 CLAHRC West, 9th floor, Whitefriars, Lewins Mead, Bristol BS1 2NT, UK 


\section{Introduction}

It has been proposed that psychosis is an extended phenotype ranging from occasional psychotic experiences (PEs) and no dysfunction to psychotic disorder with serious dysfunction [1]. Studies report that community PEs (i.e., in non-clinical populations) are strongly associated with later psychotic disorder $[2,3]$ and share risk factors with psychotic disorder [1].

Prevention of psychotic disorders is desirable, but difficult without accurate identification of those at risk before illness onset. Understanding the development of PEs and the identification of risk factors for PEs may be useful, since these often occur before psychotic disorder onset. There has been considerable debate about the true relevance of community PEs which are frequently co-morbid with depressive symptoms (DSs) [4, 5]. The strong overlap between PEs and DSs [6] suggests that PEs may be an expression of underlying emotional distress, rather than an indicator of psychosis vulnerability. In view of this it is not surprising that many risk factors for PEs are also associated with DSs and vice versa [7]. Unpicking the complex associations between risk factors and PEs which are comorbid with DSs is important, because it may help detect those at specific risk of later psychosis, inform the development of interventions to reduce psychosis incidence, and be informative for understanding the aetiology and mechanism of PEs. Previously, researchers have compared the strength of associations across studies and reported that risk factors associated with schizophrenia seem to be more strongly associated with PEs than DSs; however, these conclusions may be invalid because of differences in study populations. Others have compared estimates of association within the same study $[8,9]$, but statistical methods that account for the co-morbidity between PEs and DSs are required to address this question robustly. As far as the authors are aware only one previous study has used joint outcome modelling to investigate specific and shared risk factors between PEs and DSs, which reported that only neuro-developmental risk factors were not shared [7].

Social cognitive ability and locus of control (LoC) may be important. There is evidence that deficits in social cognition and an external LoC styles are associated with psychosis [10-15]. Social cognition (the ability to process and use social information) consists of several inter-connected, concurrent processes; the perception, storage, interpretation and implementation of social information. These processes are used to understand and interpret the actions of others and predict their future goals, intentions, and actions, and in turn to adapt one's own behaviour. The theories of Frith [16, 17] suggest that the signs and symptoms of schizophrenia can be explained by poor social cognitive ability and a consequent inability to infer the mental states of others. There is some cross-sectional evidence from small studies of an association between certain domains of social cognition and PEs or schizotypy (personality characteristics resembling psychotic symptoms), such as theory of mind [18-21], emotion recognition [19, 22-28], and social perception [19, 25]. Longitudinal studies of social cognition have produced conflicting findings. One found an association between theory of mind at age 5 and PEs at age 12 [29] but not between PEs and the recognition of emotion from faces [30].

LoC is the cognitive approach used to attribute causes to events and is related to social cognition, because it relies on self-awareness. Inevitably, individuals draw on their own belief systems to explain the world around them. An external LoC attributes negative events to external causes which are outside the control of the individual, whereas an internal LoC attributes negative events to flaws within oneself. It has been suggested [31] that an external LoC may be associated with PEs, such as paranoia, where an individual may erroneously perceive a threat from an external agent but no evidence that an external LoC is associated with DSs. There is some crosssectional evidence of an association between an external local of control and PEs or schizotypy [21, 32]. In addition, two prospective studies $[15,33]$, one using the same data source as this study [15], found that an externalised LoC is associated with PEs at age 12 and psychotic disorder. The study by Thompson et al. [15] differs from our own, because it only investigated the association between LoC at age 8 with PEs at age 12 and did not investigate the role of co-morbid DSs. The finding that only risk factors with a neuro-developmental origin are specific to PEs [7] may have relevance for the investigation of social cognitive ability and LoC as risk factors, because it has been reported that poor social cognitive ability has a neuro-developmental origin, suggesting that it is specific to PEs rather than DSs [34].

Most previous studies investigating social cognitive ability and LoC and PEs, with the exception of one [33], have focussed on childhood ability and early adolescent PEs. It is possible that social cognitive ability and LoC may be a stronger risk factor for later PEs. Although some social cognitive abilities develop early, others may develop (or become more refined) in adolescence. In addition, the demands on social cognitive ability may be more pressing in adolescence when social functioning becomes more important. Our hypothesis, therefore, is that social cognitive ability and LoC are specifically associated with PEs but not with DSs.

\section{Aims of the study}

To investigate;

1. whether childhood social cognitive abilities and LoC are associated with the early and late adolescent PEs 
and DSs. We hypothesise that social cognitive ability will be specifically associated with PEs and that an externalised LoC will be positively associated with PEs but not associated with DSs.

2. the time-varying effects of social cognitive abilities and LoC on DSs and PEs.

\section{Methods}

\section{Avon Longitudinal Study of Parents and Children (ALSPAC)}

The study sample consists of ALSPAC http://www.alspac. bris.ac.uk participants, an ongoing population-based study investigating a wide range of influences on the health and development of children. All pregnant women resident in the former Avon Health Authority in South West England with an estimated delivery date of between 1st April 1991 and 31st December 1992 were invited to participate. The children of 15,247 pregnancies were recruited. Of this sample of 15,458 foetuses, 14,701 were live births and were alive at 1 year of age [35]. Among these, 7058 children had at least one outcome of interest (DSs or PEs in the early or late adolescence) or at least one risk factor of interest and were included in the analysis. The sample is representative of those born at that time in the former county of Avon during this period [36].

\section{Ethics}

Ethical approval for the study was obtained from the ALSPAC Ethics and Law Committee and the Local Research Ethics Committee.

\section{Outcome measures}

PEs at 18 years

The Psychosis-Like Symptom interview (PLIKSi) [37] is a semi-structured instrument that draws on the principles of standardised clinical examination developed for the Schedule for Clinical Assessment in Psychiatry (SCAN) [38]. This measure is further described in Appendix A.

\section{PEs at 12 years}

The procedure for rating PEs at this timepoint was identical to that at 18 except participants were asked about experiences since their last birthday. Inter-rater reliability across all interviewers was very good $(\mathrm{Kappa}=0.72)$ according to the standard benchmarks [39].
DSs at 18 and 12 years

Self-reported DSs were assessed using the Short Moods and Feeling Questionnaire (SMFQ) [40] which asked about symptoms over the previous 2 weeks. The version of the questionnaire used in this analysis consists of only 12 questions. Question 4 "teenager felt restless" was not used because previous work found that this question was poorly understood [41]. Each question had three possible responses: 0 never, 1 sometimes, and 2 always. The score range for each participant was 0 to 24 and higher scores indicated more DSs. The internal reliability of the SMFQ is good (Cronbach's alpha $=0.85$ ) [40]. The distribution of scores on the SMFQ is highly skewed with the majority reporting low levels of symptoms; therefore, we dichotomised the scale, defining high levels of DSs by scores of $\geq 11$. This cutoff has been shown to have a high sensitivity and specificity [42] and has been previously applied in community samples [43]. Dichotomising DSs allowed joint modelling of both DSs and PEs, as described in the "Statistical analysis".

\section{Risk factors}

\section{Locus of control measures}

LoC at 8 and 16 years The shortened version of the Childhood Nowicki-Strickland Internal-External (CNSIE) questionnaire was used to measure external LoC [44]. Questions were asked during an assessment clinic at age 8. At age 16, the questions formed part of a self-completed postal questionnaire, which has good construct validity and test-retest reliability [44]. An external LoC score was calculated as the number of external responses (externality). Higher scores resent a more externalised style.

To investigate the association with outcomes at 18 years scores, externality at 8 and 16 years were used as risk factors. To investigate the association with outcomes at 12 years, externality at 8 years was used as the risk factor.

\section{Social cognitive measures}

\section{Social communication and social skills}

This was assessed using the Social Communication Disorders Checklist [45] (SCDC) which was completed by parents on behalf of their children at ages 7, 10, 13, and 16 years. The SCDC has excellent internal consistency $(0.93)$ and high test-retest reliability (0.81) [45]. A mean of the scores at 7 and 10 years was investigated in conjunction with the 12-year-old outcomes, and a mean score of the 11and 13-year-old measures was investigated in confunction with the 18-year-old outcomes. 


\section{Emotion perception: facial emotions at age 8}

Data were collected using the Diagnostic Analysis of NonVerbal Accuracy (DANVA) [46] during an annual assessment clinic held when the cohort were approximately 8 years. The faces subtest of the DANVA consists of 24 colour photos of male and female primary school age child faces, with each face showing fear, happiness, sadness, or anger. The photos were presented for $2 \mathrm{~s}$ after which the participant was asked to respond by indicating which emotion was displayed. Pictures were classified as high (easy to identify) or low (harder to identify) intensity. The test was computerised and exhibits good internal consistency reliability $(0.68-0.88)$ and good test retest reliability $(0.70-0.86)$ [46]. In these analyses, the number of errors made for each emotion with high- and low-intensity stimuli was used.

\section{Emotion perception: biological movement at 12 years}

This was assessed during the same clinic as the PLIKSi using the Emotional Triangles test [47]. This computerised test consists of silent animations with a black outline triangle and circle on a white background. The movements of the animated shapes were designed to represent the way a person might move if affected by the target emotion. For instance, scared was depicted by the triangle 'jabbing' at the circle. The shapes appeared to interact in a manner appropriate to one of four basic emotions; happy, sad, angry, and scared. For each of the four emotion trials, two different types of questions are asked: one that is emotionappropriate ("is the triangle happy?" for a happy animation) and one that is not ("is the triangle happy?" for a sad/ angry/scared animation). Inappropriate responses were subtracted from appropriate responses to account for response bias. High scores represent a better performance. This risk factor was only investigated in relation to the 18-year-old outcomes.

\section{Potential confounding variables}

These were chosen using knowledge of variables which may be associated with PEs and DSs in general population samples and from previous relevant research. Those selected were gender, maternal marital, and educational status at the child's birth, child's IQ at age 8 collected using the alternate items from the Wechsler Intelligence Scale for Children (WISC) [48] and the number of autistic traits between ages 6 months and 9 years [49].

Figure 1 depicts the time line for data collection points.

\section{Data preparation}

\section{Missing data}

Multiple imputation of missing data was conducted by fully conditional specification using flexible additive imputation models as implemented in the 'aregImpute' function in the R statistical package $[50,51]$ (see Appendix B for further information).

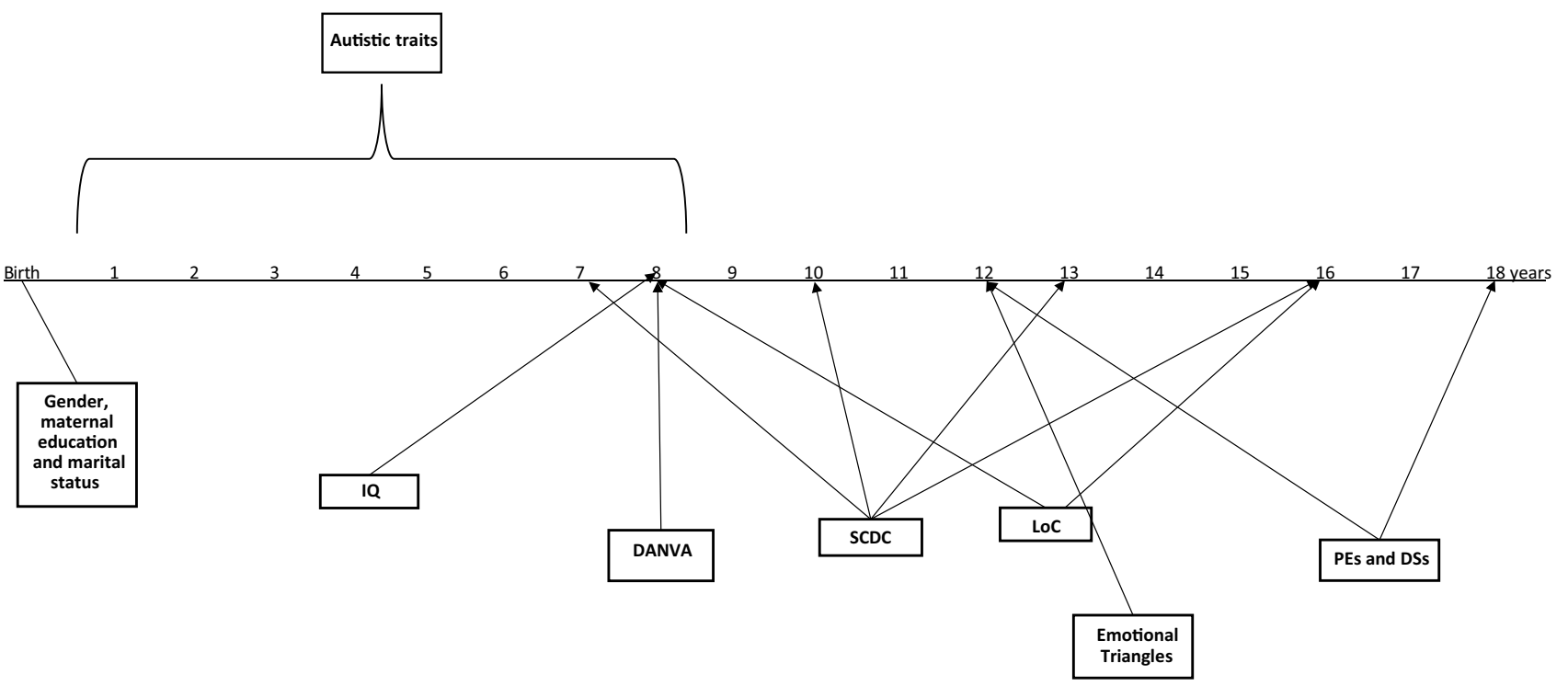

Fig. 1 Timeline. A time line of data collection points. Key: DANVA Diagnostic Analysis of Non-Verbal Accuracy, SCDC Social and Communication Disorders Checklist, $P E$ psychotic experiences, $D S$ depressive symptoms, $L O C$ locus of control 


\section{Statistical analysis}

Standardised versions of risk factor and confounder variables were used for analyses. Initially, the associations between externality and social cognitive ability and PEs at 12 and 18 years and DSs at 12 and 18 years were investigated using logistic regression modelling in imputed data. Multivariable models were used to adjust for confounders and the corresponding psychopathology at each timepoint.

Second, four-dimensional probit regression models were used to jointly model the binary indicators of PEs and DSs at each time-point and to compare regression parameter outcomes using Wald tests after imputation using Stata [52], R [53] and MLwiN [54] software packages. We converted probit estimates into odds ratios to enable interpretability by obtaining approximations of the logit parameters by multiplying the probit parameters by a factor of 1.6 [55].

Joint modelling of depression and PEs at 12 and 18 years allows us to examine whether increases in the levels of social communication, externality and emotion perception could change the risk of depression and PE at each timepoint. The joint modelling approach estimates all these effect simultaneously in a single model and thus allows us to compare these effects (as quantified through odds ratios). The comparison of such effects automatically translates to: (a) compare effects between outcomes, e.g., whether externality at 8 years has a similar association with the risk of depression and PE at 12 years and similarly whether externality at 16 years has a similar association with depression and PE at 18 years (in other words whether each exposure is common or specific to each psychopathology) and

(b) compare effects across time, e.g., whether externality at 8 and 16 years has a similar effect for depression at 12 and depression at 18 years, respectively (in other words, test whether externality has a time-dependent effect on depression or PE).

\section{Results}

\section{Descriptive data}

Participants were slightly more likely to be female and have a mother who was married at their birth who did not have a higher education qualification compared to the overall sample (Table 1). This was as expected from the ALSPAC cohort follow-up [35, 56]. The proportion of those with PEs decreased between 12 and 18 years, whereas the proportion with DSs increased. Imputed data used in this analysis differed little from observed data (Supplementary Table A).
Table 1 Description of risk factors, outcome variables, and participants

\begin{tabular}{|c|c|c|c|c|}
\hline Measure & Scale & Analysis units & Sample $N$ & $N(\%)$ exposed \\
\hline \multicolumn{5}{|l|}{ Confounders } \\
\hline Sex & Binary & Female & 7058 & $3645(51.6 \%)$ \\
\hline Marital status of mother & Binary & Not married & 6703 & $963(14.4 \%)$ \\
\hline Low maternal education & Binary & CSEs/O-levels & 6604 & $3785(57.3 \%)$ \\
\hline IQ 8 years & WISC (45-151) & $\operatorname{NED}(1 \mathrm{sd}:=15)^{(* *)}$ & 5665 & \\
\hline Autistic traits 6 months -9 years & $0-93$ & $\operatorname{NED}(1 \mathrm{sd}:=17)^{(* *)}$ & 6968 & \\
\hline \multicolumn{5}{|l|}{ Main risk factors } \\
\hline Social communication 7 years & $0-24$ & $\operatorname{NED}(1 \mathrm{sd}:=3)^{(* *)}$ & 5674 & \\
\hline Social communication 10 years & $0-12$ & $\operatorname{NED}(1 \mathrm{sd}:=0.5)^{(* *)}$ & 5631 & \\
\hline Social communication 11 years & $0-12$ & $\operatorname{NED}(1 \mathrm{sd}:=0.6)^{(* *)}$ & 5471 & \\
\hline Social communication 13 years & $0-12$ & $\operatorname{NED}(1 \mathrm{sd}:=0.7)^{(* *)}$ & 4457 & \\
\hline LoC externality 8 years & $0-12$ & $\operatorname{NED}(1 \mathrm{sd}:=2)^{(* *)}$ & 5050 & \\
\hline LoC externality 16 years & $0-13$ & $\operatorname{NED}(1 \mathrm{sd}:=2)^{(* *)}$ & 3876 & \\
\hline DANVA 8 years & $0-22$ & $\operatorname{NED}(1 \mathrm{sd}:=0.4)^{(* *)}$ & 5390 & \\
\hline Emotional triangles 12 years & $(-6)-20$ & NED (1sd:=4) & 5387 & \\
\hline \multicolumn{5}{|l|}{ Outcomes } \\
\hline DSs at 12 years & (MFQ) 0-25 & $\geq 11$ score & 6343 & $443(6.9 \%)$ \\
\hline DSs at 18 years & (CISR) 0-39 & $\geq 12$ score & 4288 & $655(15.3 \%)$ \\
\hline PEs at 12 years & (PLIKS) Binary & Presence & 6272 & $859(13.7 \%)$ \\
\hline PEs at 18 years & (PLIKS) Binary & Presence & 4438 & $411(9.3 \%)$ \\
\hline
\end{tabular}

${ }^{(* *)} N E D$ Normal Equivalent Deviate-standardised scale. Raw scores are transformed to z-scores (standard normal scores) using the inverse normal function 


\section{Common and specific risk factors}

Tables 2 and 3 show unadjusted and adjusted associations between the social cognitive variables and PEs and DSs.

\section{External LoC (externality)}

In unadjusted analyses, there was evidence that externality at ages 8 and 16 years was associated with PEs and DSs at ages 12 and 18 years. Externality was associated with a higher risk of PEs than DSs and was sustained over time. The association between externality at age 8 years and PEs at 12 years was stronger than with DSs at 12 years, but at 18 years, the risk for DSs had converged to be similar in size. Adjustment for confounding caused some effect attenuation along with larger standard errors, as expected. There was weak evidence of a difference in the strength of the association with PEs across time, where a 1 SD increase in externality at age 8 years was associated with a $23 \%$ increase in the odds of PEs at 12 years and a $38 \%$ increase at 18 years with externality at 8 and 16 years. There was strong evidence that the association between externality at 8 and 16 years and DSs at age 18 was stronger than that with externality at 8 years and DSs at age 12 with each SD increase in externality associated with a $40 \%$ increase in the odds of DSs at 18 compared to a $12 \%$ increase at 12 years. There was weak evidence that the association across psychopathologies was different at 12 years (stronger for PEs than DSs) but no evidence of a difference at 18 years, where the risks converged.

Table 2 Results using probit modelling: risk factor effects (OR and 95\% CIs) on depression and PEs at 12 and 18 years $(N=7058)$, respectively and averaged over 100 imputations for missing data, as described in "Methods"

\begin{tabular}{|c|c|c|c|c|c|c|c|c|}
\hline & \multirow[t]{3}{*}{ Age } & \multicolumn{2}{|l|}{ DSs* } & \multicolumn{2}{|l|}{ PEs* } & \multicolumn{3}{|l|}{ Wald tests } \\
\hline & & & & & & DSs & PEs & Common effect \\
\hline & & OR & $95 \% \mathrm{CI}$ & OR & $95 \% \mathrm{CI}$ & $\begin{array}{l}\text { Time effects } \\
t \text { stat. }(p \text { val. })^{\mathrm{a}}\end{array}$ & $\begin{array}{l}\text { Time effect } \\
t \text { stat. }(p \text { val. })^{\mathrm{b}}\end{array}$ & $\begin{array}{l}12 \text { years } \\
18 \text { years }^{\mathrm{c}}\end{array}$ \\
\hline \multicolumn{9}{|l|}{ Socio-demographic } \\
\hline \multirow[t]{2}{*}{ Female } & 12 & 1.58 & {$\left[\begin{array}{lll}1.36 & 1.84\end{array}\right]$} & 1.14 & {$\left[\begin{array}{lll}1.00 & 1.29\end{array}\right]$} & \multirow[t]{2}{*}{$-3.03(0.002)$} & \multirow[t]{2}{*}{$-1.64(0.102)$} & $3.60(<0.0001)$ \\
\hline & 18 & 2.14 & {$\left[\begin{array}{lll}1.85 & 2.47\end{array}\right]$} & 1.32 & {$\left[\begin{array}{ll}1.13 & 1.54\end{array}\right]$} & & & $4.81(<0.0001)$ \\
\hline \multirow[t]{2}{*}{ Marital status unmarried } & 12 & 1.22 & {$\left[\begin{array}{lll}0.98 & 1.51]\end{array}\right.$} & 1.32 & {$\left[\begin{array}{ll}1.11 & 1.56\end{array}\right]$} & \multirow[t]{2}{*}{$-0.62(0.534)$} & \multirow[t]{2}{*}{$-2.02(0.043)$} & $-0.64(0.525)$ \\
\hline & 18 & 1.33 & {$\left[\begin{array}{lll}1.10 & 1.60\end{array}\right]$} & 1.69 & {$\left[\begin{array}{lll}1.37 & 2.08\end{array}\right]$} & & & $-1.88(0.060)$ \\
\hline \multirow[t]{2}{*}{ Low maternal education } & 12 & 1.07 & {$\left[\begin{array}{lll}0.92 & 1.25\end{array}\right]$} & 1.19 & {$\left[\begin{array}{lll}1.04 & 1.35\end{array}\right]$} & \multirow[t]{2}{*}{$0.07(0.946)$} & \multirow[t]{2}{*}{$-1.78(0.076)$} & $-1.12(0.263)$ \\
\hline & 18 & 1.07 & {$\left[\begin{array}{ll}0.93 & 1.23\end{array}\right]$} & 1.41 & {$\left[\begin{array}{ll}1.20 & 1.66]\end{array}\right.$} & & & $-2.83(0.005)$ \\
\hline \multicolumn{9}{|l|}{ Main risk factors } \\
\hline \multirow[t]{2}{*}{ LoC externality (time-varying) } & 12 & 1.15 & {$\left[\begin{array}{ll}1.05 & 1.25\end{array}\right]$} & 1.26 & {$\left[\begin{array}{ll}1.18 & 1.36\end{array}\right]$} & \multirow[t]{2}{*}{$-3.42(0.001)$} & \multirow[t]{2}{*}{$-1.72(0.087)$} & \multirow[t]{2}{*}{$-1.93(0.054)$} \\
\hline & 18 & 1.41 & {$\left[\begin{array}{lll}1.29 & 1.53\end{array}\right]$} & 1.41 & {$\left[\begin{array}{lll}1.26 & 1.58\end{array}\right]$} & & & \\
\hline \multirow[t]{2}{*}{ Social communication (time-varying) } & 12 & 1.21 & {$\left[\begin{array}{lll}1.10 & 1.33\end{array}\right]$} & 1.08 & {$\left[\begin{array}{lll}1.00 & 1.17\end{array}\right]$} & \multirow[t]{2}{*}{$0.32(0.751)$} & \multirow[t]{2}{*}{$-0.6(0.546)$} & $1.86(0.064)$ \\
\hline & 18 & 1.19 & {$\left[\begin{array}{ll}1.08 & 1.30\end{array}\right]$} & 1.13 & {$\left[\begin{array}{ll}1.01 & 1.26\end{array}\right]$} & & & $0.78(0.433)$ \\
\hline \multirow[t]{2}{*}{ DANVA 8 years } & 12 & 0.96 & {$\left[\begin{array}{lll}0.89 & 1.04\end{array}\right]$} & 0.92 & {$\left[\begin{array}{lll}0.86 & 1.00\end{array}\right]$} & \multirow[t]{2}{*}{$0.49(0.623)$} & \multirow[t]{2}{*}{$-1.33(0.184)$} & $0.8(0.426)$ \\
\hline & 18 & 0.94 & {$\left[\begin{array}{lll}0.88 & 1.01]\end{array}\right]$} & 0.99 & {$\left[\begin{array}{lll}0.91 & 1.07\end{array}\right]$} & & & $-1.01(0.311)$ \\
\hline \multirow[t]{2}{*}{ Emotional triangles } & 12 & & & & & & & \\
\hline & 18 & 1.07 & {$\left[\begin{array}{lll}1.00 & 1.14\end{array}\right]$} & 1.05 & {$\left[\begin{array}{lll}0.97 & 1.13\end{array}\right]$} & & & $0.34(0.731)$ \\
\hline \multicolumn{9}{|l|}{ Confounders } \\
\hline \multirow[t]{2}{*}{ IQ } & 12 & 0.90 & {$\left[\begin{array}{lll}0.83 & 0.97\end{array}\right]$} & 0.86 & {$\left[\begin{array}{lll}0.80 & 0.92\end{array}\right]$} & \multirow[t]{2}{*}{$-1.81(0.071)$} & $-0.85(0.398)$ & $0.92(0.359)$ \\
\hline & 18 & 0.98 & {$\left[\begin{array}{ll}0.91 & 1.06\end{array}\right]$} & 0.89 & [0.82 0.97$]$ & & & $1.92(0.055)$ \\
\hline Autistic traits & 12 & 1.08 & [1.00 1.17] & 1.12 & [1.05 1.20$]$ & $0.72(0.469)$ & $-0.55(0.583)$ & $-0.84(0.401)$ \\
\hline & 18 & 1.04 & {$\left[\begin{array}{lll}0.97 & 1.12\end{array}\right]$} & 1.15 & [1.07 1.25$]$ & & & $-2.07(0.039)$ \\
\hline
\end{tabular}

*Analysis scale is expressed in the standard deviation units, where the scale is transformed to have a mean 0 and $\mathrm{SD}=1$

${ }^{a}$ Test of evidence against the null hypothesis that the strength of the association between risk factors and depression modelled separately at each timepoint is equal to the strength of the association between risk factors and depression modelled across timepoints

${ }^{b}$ Test of evidence against the null hypothesis that the strength of the association between risk factors and psychotic experiences modelled separately at each timepoint is equal to the strength of the association between risk factors and psychotic experiences modelled across timepoints

${ }^{c}$ Test of evidence against the null hypothesis that the strength of the association between risk factors and the psychopathologies modelled separately at each timepoint is equal to the strength of the association between the risk factors and both psychopathologies modelled together at each timepoint 
Table 3 Main risk factor effects (OR and 95\% CIs) on depression and psychotic experiences (PEs) at 12 and 18 years, adjusted for socio-demographic and confounding variables $(N=7058)$, respectively and averaged over 100 imputations for missing data, as described in "Methods"

\begin{tabular}{|c|c|c|c|c|c|c|c|c|}
\hline & \multirow[t]{3}{*}{ Age } & \multicolumn{2}{|l|}{ DSs* } & \multicolumn{2}{|c|}{ PEs* } & \multicolumn{3}{|l|}{ Wald tests } \\
\hline & & & & & & DSs & PEs & Common \\
\hline & & OR & $95 \% \mathrm{CI}$ & OR & $95 \% \mathrm{CI}$ & $\begin{array}{l}\text { Time effects } \\
t \text { stat. }(p \text { val. })^{\mathrm{a}}\end{array}$ & $\begin{array}{l}\text { Time effect } \\
t \text { stat. }(p \text { val. })^{\mathrm{b}}\end{array}$ & $\begin{array}{l}12 \text { years } \\
18 \text { years }^{\mathrm{c}}\end{array}$ \\
\hline \multicolumn{9}{|l|}{ Main Risk factors } \\
\hline \multirow[t]{2}{*}{ LoC externality (time-varying) } & 12 & 1.12 & {$\left[\begin{array}{ll}1.02 & 1.22\end{array}\right]$} & 1.23 & {$\left[\begin{array}{lll}1.14 & 1.33\end{array}\right]$} & \multirow[t]{2}{*}{$-3.57(<0.0001)$} & \multirow[t]{2}{*}{$-1.66(0.098)$} & $-1.87(0.061)$ \\
\hline & 18 & 1.40 & {$\left[\begin{array}{ll}1.28 & 1.52\end{array}\right]$} & 1.38 & {$\left[\begin{array}{ll}1.23 & 1.55\end{array}\right]$} & & & $0.13(0.894)$ \\
\hline \multirow[t]{2}{*}{ Social communication (time-varying) } & 12 & 1.22 & {$\left[\begin{array}{ll}1.11 & 1.34\end{array}\right]$} & 1.06 & {$\left[\begin{array}{lll}0.98 & 1.15\end{array}\right]$} & \multirow[t]{2}{*}{$0.16(0.870)$} & \multirow[t]{2}{*}{$-0.78(0.438)$} & $2.22(0.027)$ \\
\hline & 18 & 1.21 & {$\left[\begin{array}{ll}1.10 & 1.33\end{array}\right]$} & 1.12 & {$\left[\begin{array}{lll}1.00 & 1.25\end{array}\right]$} & & & $1.08(0.282)$ \\
\hline \multirow[t]{2}{*}{ DANVA 8 years } & 12 & 0.95 & {$\left[\begin{array}{lll}0.87 & 1.03\end{array}\right]$} & 0.90 & {$\left[\begin{array}{lll}0.83 & 0.98\end{array}\right]$} & \multirow[t]{2}{*}{$-0.21(0.836)$} & \multirow[t]{2}{*}{$-1.59(0.112)$} & $0.93(0.353)$ \\
\hline & 18 & 0.96 & {$\left[\begin{array}{ll}0.89 & 1.03\end{array}\right]$} & 0.98 & {$\left[\begin{array}{ll}0.90 & 1.06\end{array}\right]$} & & & $-0.45(0.655)$ \\
\hline \multirow[t]{2}{*}{ Emotional triangles } & 12 & & & & & & & \\
\hline & 18 & 1.09 & [1.02 1.17] & 1.08 & {$\left[\begin{array}{ll}1.00 & 1.16\end{array}\right]$} & & & $0.24(0.808)$ \\
\hline
\end{tabular}

*Analysis scale is expressed in the standard deviation units, where the scale is transformed to have a mean 0 and $\mathrm{SD}=1$;

${ }^{a}$ Test of evidence against the null hypothesis that the strength of the association between risk factors and depression modelled separately at each timepoint is equal to the strength of the association between risk factors and depression modelled across timepoints

${ }^{b}$ Test of evidence against the null hypothesis that the strength of the association between risk factors and psychotic experiences modelled separately at each timepoint is equal to the strength of the association between risk factors and psychotic experiences modelled across timepoints

${ }^{\mathrm{c}}$ Test of evidence against the null hypothesis that the strength of the association between risk factors and the psychopathologies modelled separately at each timepoint is equal to the strength of the association between the risk factors and both psychopathologies modelled together at each timepoint

\section{Social communication}

Unadjusted associations showed marginal evidence of an association with PEs at either age, whereas there was evidence of an association between social communication ability at age 7 and 10 years and DSs at 12 years and between social communication ability at 13 and 16 years and DSs at 18 years. After adjustment, there was still only marginal evidence of an association with PEs at either timepoint, however, the association with DSs at both ages remained. At 12 and 18 years, each SD increase in poor social communication ability was associated with an approximate $20 \%$ increase in the odds of DSs There was no evidence that the association with either psychopathology differed over time (PEs $p=0.44$, DSs $p=0.87$ ). There was marginal evidence $(p=0.03)$ that the association at age 12 was specific to DSs but no evidence of disorder-specific effects at 18 years $(p=0.28)$.

\section{Emotion perception}

In unadjusted analyses, there was evidence of a weak association between emotion perception using biological movement at age 12 years and DSs at 18 years but no evidence of an association with PEs at 18 years. There was no evidence of any association between emotion perception ability (facial expression) at 8 years and either psychopathology at 12 or 18 years. After adjustment for confounders, there was weak evidence of an association between emotion perception (biological movement) at 12 years and both PEs and DSs at 18 years. A 1 SD increase in emotion perception ability was associated with a $9 \%$ increase in the odds of DSs and an $8 \%$ increase in the risk of PEs at 18 years, but the associated uncertainties were large, and could be largely due to measurement error. There remained no evidence of an association between emotion perception (facial expression) and either psychopathology at either age. These findings are illustrated in Fig. 2a-d. The associations between each risk factor and each outcome using logistic regression modelling are described in Supplementary Table B.

\section{Discussion}

Our hypothesis that increased externality and reduced social cognitive ability would be specifically associated with increased risk of PEs was partially supported, since there was some evidence that externality had a stronger impact on the risk of PEs at 12 years than on DSs. However, whilst the association with PEs was time-invariant, it was no longer specific to PEs by age 18 . In contrast, there 

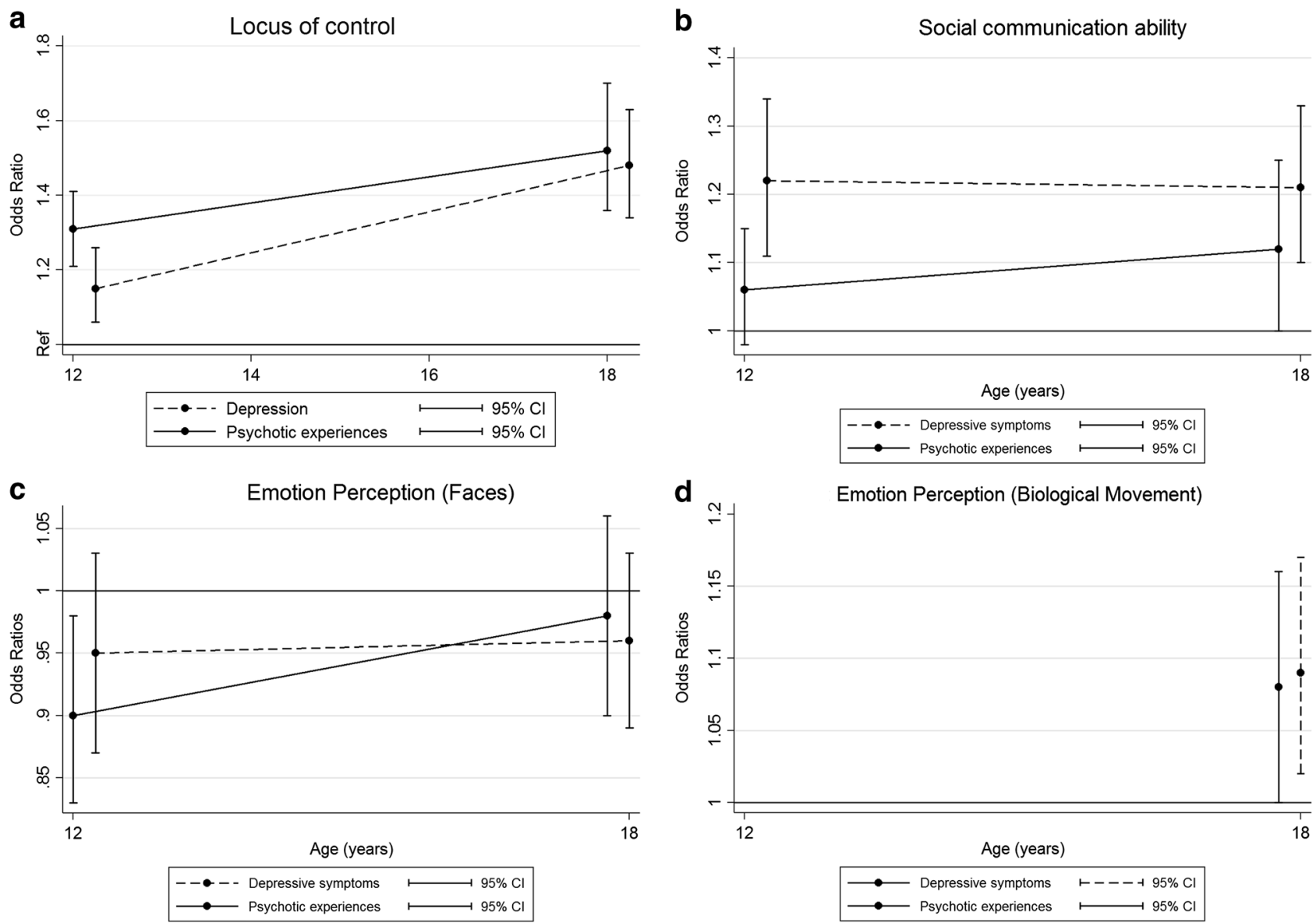

Fig. 2 a Locus of control, b social communication ability, c emotion perception (faces), and $\mathbf{d}$ emotion perception (biological movement)

was evidence that social communication deficits were more specific to DSs than PEs at 12 years and there was no evidence that emotion perception was specific to either.

Our findings are in support of the only other longitudinal study on an externality at age 8 and PEs at age 12, which uses data from the same cohort [15]. Our study extends these findings, by simultaneously modelling PEs and DSs in the early and late adolescence. The size of the association detected in this study is larger than our own, which may be because this study did not account for co-morbid depression. Our results suggest that externality is also associated with depression at 12 years, and therefore, a failure to account for this would inflate the estimate. Our findings also support the only other longitudinal study reporting an association between early externality and later psychotic disorder [15, 33]. It is difficult to compare this report of a strong association with ours, since they are expressed as a likelihood ratio Chi-squared for schizophrenia and schizophrenia-spectrum disorder. The difference in the size of associations may be because the outcome was measured in a clinical sample rather than a community sample, or because the participants were from a high-risk group. If psychotic disorders are on a continuum with PEs, associations between risk factors and outcomes are likely to be stronger at the severe end of the continuum. The sample size was also smaller than ours $(n=89)$, and it is increasingly recognised that very small sample sizes can be associated with effect inflation [57]. There was also no adjustment for confounding and, in particular given our findings, of co-morbid depression.

Our findings also expand the previous work in this cohort that investigated the association between emotion perception ability and PEs [30]. This study also failed to find an association.

\section{Externality, social cognitive ability, and psychopathology}

Our findings suggest that externality and poor social communication are potential predictors of later DSs and PEs, even after accounting for co-morbidity and confounding. It is also true that, in general, externality was associated with PEs and poor social communication ability was 
more strongly associated with DSs. It is easy to speculate how these deficits may lead to each psychopathology. Externality, whereby negative events are attributed to other people or externally-controlled circumstances, may lead to paranoia and delusional belief [31], whereas poor social communication may cause social isolation, leading to DSs. Some psychotic symptoms, such as hallucinations, are associated with a blurring of the boundary of the self, which may be exacerbated by an external LoC which blames self-created negative events on external factors.

It is interesting that in general, associations were stronger for both psychopathologies at 18 than at 12 years, in spite of the fact that PEs are less prevalent in late adolescence. There are several possible explanations for this. It may be that the demands on social cognitive ability are greater in late adolescence, with growing social independence and more complex social tasks. It may also be that PEs at 12 are less accurately measured, perhaps because younger adolescents had difficulty understanding the questions, and therefore, measurement error is diluting the associations between PEs at 12 years and the risk factors. This possibility is endorsed by the lower inter-rater reliability statistics at 12 compared to 18 years. Another possibility is that PEs that have either persisted since age 12 , or have been incident since age 12, are of a more severe nature and, therefore, have a stronger association with risk factors.

\section{The specificity of externality and social cognitive ability as a predictor for PEs}

Our hypothesis that externality and poor social cognition would be specifically associated with PEs was based on existing evidence that poor social cognition precedes psychosis, but little evidence that poor social cognition precedes depression [58]. Furthermore, there is a strong evidence that neuro-developmental abnormalities are associated with the risk of schizophrenia [59] and PEs [37].

We found little evidence that associations between externality, social cognitive ability and psychopathology at 18 years were specific to PEs, although at 12 years, there was marginal evidence of this. There are a number of potential explanations. First, PEs in this general population sample may not be strong indicators of aetiological mechanisms underlying psychotic disorders, but may be more representative of emotional distress akin to depression and anxiety; indeed, there is increasing evidence to support this view [60]. Second, it may be that poor social cognition is only a predictor for more severe PEs which are more likely to be associated with later psychotic disorder and there may be an insufficient number of 'severe' PEs in our sample. Third, it may only be severe forms of social cognitive dysfunction that are neuro-developmental in origin and there may be few participants with this type of severe social cognitive dysfunction in our sample. Fourth, we used a broad measure of PEs (i.e., both suspected and definite experiences), which may be more similar to DSs than the definite PEs would have been.

It is interesting to speculate why the only indication of specificity was at age 12. It is possible that at the earlier timepoint, there is less overlap between PEs and DSs and that this difference emerged, in spite of the greater difficulty of measuring PEs at 12 compared to 18 years. If it had been possible to measure PEs at the earlier timepoint with even greater accuracy, we may have been able to detect specificity with greater precision.

\section{Strengths and limitations}

To our knowledge, this is the first study to simultaneously model PEs and DSs in the early and late adolescence. This has enabled us to explore the complex relationship between these psychopathologies and the specificity of externality and social cognition as risk factors using a robust statistical method.

This study uses prospective data from a large cohort of adolescents from a general population sample which is representative of the UK population of adolescents [35]. Multiple imputation was used to replace missing data, which has helped to reduce the effect of selection bias resulting from the loss to follow-up of cohort members.

Some limitations of this study should also be acknowledged. There is no measure of PEs before 12 years, which makes it impossible to be certain that the risk factors preceded PEs. However, it should also be acknowledged that measurement of PEs in young children is unlikely to be accurate. The assessment periods for each timepoint of the PEs interviews were different. At 12 years, the participants were asked about any experiences since their 12th birthday (i.e., over the previous 6 months), whereas at 18 years, they were asked about experiences since their 12th birthday (i.e., over 6 years). It is difficult to know what difference this methodological weakness may have had. Potentially, the accuracy of the recall of the participants could have been better at 12 years, as they were being asked to recall experiences over a shorter period. This should have reduced measurement error and thereby increased the probability of detecting an association between risk factors and the 12-year outcomes. However, the probability of recalling an experience may have been greater at the 18-year interview as the participants were asked about experiences which may have occurred over a much longer period, especially if the experiences only happened infrequently. This could have resulted in the recording of a greater number of outcomes, which would also have increased the statistical power to detect an association between risk factors and 
outcomes. Another limitation is that there were no data recorded in the cohort on confirmed physician diagnosis of either psychosis or depression at 12 or 18 years, although these variables have been subsequently derived from the data by other authors [3]. This is a less important limitation, however, since the aim of this study was to investigate risk factors for PEs and DSs rather than for actual diagnoses, which are in any case likely to be very infrequent at these ages.

Some of the social cognitive measures used here are blunt and may not provide an accurate measure of ability. An additional source of risk factor measurement error may be because some data was collected from parental report (social communication). There are also no data on theory of mind ability in the ALSPAC cohort. It would have been interesting to investigate this ability as a risk factor, since there is convincing evidence that it is associated with psychosis [10, 12].

The importance of PEs as a predictor of psychotic disorder is still undecided, and in fact, most PEs will resolve or not lead to psychotic disorder. However, they are still of importance, since they are a reflection of emotional distress in adolescents and are associated with poor functioning.

\section{Implications}

If our results reflect the causal effect of externality and social communication deficits, then therapies aimed at improving these abilities may reduce the incidence of both PEs and DSs and potentially other psychopathologies, such as anxiety, in early and later adolescence. There is evidence that LoC is modifiable [61] and evidence that interventions to improve social cognition in children may be effective [62].

\begin{abstract}
Acknowledgements We are extremely grateful to all the families who took part in this study, the midwives for their help in recruiting them, and the whole ALSPAC team, which include interviewers, computer and laboratory technicians, clerical workers, research scientists, volunteers, managers, receptionists, and nurses. The UK Medical Research Council and the Wellcome Trust (Grant ref: 102215/2/13/2) and the University of Bristol provide core support for ALSPAC. This publication is the work of the authors, and SS, AT, DK, GL, and SZ will serve as guarantors for the contents of this paper. This research was specifically funded by the UK Medical Research Council and the Wellcome Trust (Grant ref 092731).
\end{abstract}

Compliance with ethical standards

Conflict of interest The authors have no conflicts of interest to declare.

Open Access This article is distributed under the terms of the Creative Commons Attribution 4.0 International License (http:// creativecommons.org/licenses/by/4.0/), which permits unrestricted use, distribution, and reproduction in any medium, provided you give appropriate credit to the original author(s) and the source, provide a link to the Creative Commons license, and indicate if changes were made.

\section{Appendix A: The psychosis-like experiences interview (PLIKSi)}

PLIKSi includes 12 'core' questions eliciting key psychotic experiences (PEs) occurring since age 12, covering hallucinations (visual and auditory), delusions (spied on, persecution, thoughts being read, reference, control, and grandiosity), and experiences of thought interference (broadcasting, insertion, and withdrawal). Any unspecified delusions elicited were also rated. Cross-questioning was used to establish the presence of symptoms, and coding of items followed the glossary definitions and rating rules for SCAN. Interviewers were psychology graduates who received training in assessment of the SCAN Psychosis Section and in using the PLIKSi. Interviewers rated symptoms as not present, suspected, or definitely present. Unclear responses after probing were always 'rated down', and symptoms only rated as definite when a credible example was provided. If an experience was rated as suspected or definite the participant was asked, whether the experiences reported were always attributable to the effects of sleep (hypnopompic or hypnogogic experiences), fever, or substance use (defined as experiences occurring only within $2 \mathrm{~h}$ of intoxication with drugs or alcohol). If this was the case, the experience was not rated as present. Interviewers discussed cases with a psychiatrist if it was unclear how an experience should be rated. At regular intervals, interviewer ratings for a sample of recorded interviews were also rated by a psychiatrist to ensure that interviewers were rating experiences correctly. The average kappa value for inter-rater reliability across the time period of data collection was 0.83 which is considered high using the standard benchmarks.

\section{Appendix B: Data imputation details}

The imputation model included approximately 60 auxiliary variables in addition to those included in the analyses that were either associated with missingness or were predictive of DSs or PEs at 18 years to make the basic assumption underlying multiple imputation realistic. These included a wide range of markers of socio-demographic characteristics during the early childhood and historical assessments of most risk factors. Further information is available from the authors. Parameter estimates were averaged over 100 imputed data sets using Rubin's rules. Wald-type tests were used following imputation to assess equality/commonality of risk factor effects. 
Pattern of missing data

\begin{tabular}{llll}
\hline Variable & Age of assessment & $n$ & $\%$ Missing \\
\hline Psychotic experiences & 18 & 4199 & 51.5 \\
& 12 & 6115 & 29.4 \\
DANVA & 8 & 6091 & 29.6 \\
Locus of control & & 1938 & 76.8 \\
& 16 & 4337 & 49.9 \\
Emotional triangles & 12 & 5113 & 40.9 \\
SCDC & 7 & 2174 & 74.9 \\
& 10 & 2441 & 71.8 \\
& 13 & 2442 & 71.8 \\
Maternal marital status & 16 & 1870 & 78.4 \\
Maternal education & Child's birth & 8656 & 0 \\
IQ & & 8656 & 0 \\
Emotion domain of SDQ & 7 & 6009 & 30.6 \\
\hline
\end{tabular}

DANVA Diagnostic Analysis of Non-verbal Accuracy. SCDC Social Communication Disorders Checklist. SDQ Strengths and Difficulties Questionnaire

\section{Extra variables used in missing data imputation}

Locus of control assessed with the Cognitive Styles Questionnaire at age 18 years.

Psychotic experiences assessed by self-report questionnaire at $11,13,14$, and 16 years.

Seven autistic traits are verbal ability, language acquisition, semantic-pragmatic skills, social understanding, repetitive behaviour, articulation, and social inhibition, which were derived from a factor analysis of 93 variables consisting of data collected between 5 and 10 years [63].

\section{References}

1. van Os J, Linscott RJ, Myin-Germeys I, Delespaul P, Krabbendam L (2009) A systematic review and meta-analysis of the psychosis continuum: evidence for a psychosis proneness-persistence-impairment model of psychotic disorder. Psychol Med 39(2):179-195

2. Werbeloff N, Drukker M, Dohrenwend BP, Levav I, Yoffe R, van Os J, Davidson M, Weiser M (2012) Self-reported attenuated psychotic symptoms as forerunners of severe mental disorders later in life. Arch Gen Psychiatry 69(5):467-475. doi:10.1001/archgenpsychiatry.2011.1580

3. Zammit S, Kounali D, Cannon M, David A, Gunnel D, Heron J, Jones P, Lewis S, Sullivan S, Wolke D, Lewis G (2013) Prevalence and prediction of psychotic experiences, prodromal syndromes and psychotic disorder at age 18 in a longitudinal, population-based cohort study. Am J Psychiatry 170(7):742-750

4. Kelleher I, Keeley H, Corcoran P, Lynch F, Fitzpatrick C, Devlin N, Molloy C, Roddy S, Clarke MC, Harley M, Arseneault L, Wasserman C, Carli V, Sarchiapone M, Hoven C,
Wasserman D, Cannon M (2012) Clinicopathological significance of psychotic experiences in non-psychotic young people: evidence from four population-based studies. Br J Psychiatry 201(1):26-32. doi:10.1192/bjp.bp.111.101543

5. Dhossche D, Ferdinand R, van der Ende J, Hofstra MB, Verhulst F (2002) Diagnostic outcome of self-reported hallucinations in a community sample of adolescents. Psychol Med 32(4):619-627

6. Sullivan S, Wiles N, Kounali D, Lewis G, Heron J, Cannon M, Mahedy L, Jones P, Stochl J, Zammit S (2014) Longitudinal associations between adolescent psychotic experiences and depressive symptoms. PLoS One. doi:10.1371/journal. pone. 0105758

7. Kounali D, Zammit S, Wiles N, Sullivan S, Cannon M, Stochl J, Jones P, Mahedy L, Gage SH, J H, Lewis G (2014) Common versus psychopathology-specific risk factors for psychotic experiences and depression during adolescence. Psychol Med 44(12):2557-2566

8. Krabbendam L, Myin-Germeys I, De Graaf R, Vollebergh W, Nolen WA, Iedema J, Van Os J (2004) Dimensions of depression, mania and psychosis in the general population. Psychol Med 34(7):1177-1186. doi:10.1017/S0033291703001892

9. Breetvelt EJ, Boks MPM, Numans ME, Selten JP, Sommer IEC, Grobbee DE, Kahn RS, Geerlings MI (2010) Schizophrenia risk factors constitute general risk factors for psychiatric symptoms in the population. Schizophr Res 120(1-3):184190. doi:10.1016/j.schres.2010.03.033

10. Bora E, Yucel M, Pantelis C (2009) Theory of mind impairment in schizophrenia: meta analysis. Schizophr Res 109:1-9

11. Brune M (2005) "Theory of Mind" in schizophrenia. A review of the literature. Schizophr Bull 31(1):21

12. Sprong M, Schothorst P, Vos E, Hox J, van Engeland H (2007) Theory of mind in schizophrenia: meta-analysis. Br J Psychiatry 191:5-13

13. Savla GN, Vella L, Armstrong CC, Penn DL, Twamley EW (2012) Deficits in domains of social cognition in schizophrenia: a meta-analysis of the empirical evidence. Schizophr Bull. doi:10.1093/schbul/sbs080

14. Penn DL, Corrigan PW, Bentall RP, Racenstein JM, Newman LS (1997) Social cognition in schizophrenia. Psychol Bull 121(1):114-132

15. Thompson A, Sullivan S, Lewis G, Zammit S, Heron J, Horwood J, Thomas K, Gunnell D, Hollis C, Wolke D, Harrison G (2011) Association between locus of control in childhood and psychotic symptoms in early adolescence: results from a large birth cohort. Cognit NeuroPsychiatry 16(5):385-402. doi:10.1 080/13546805.2010.546077

16. Frith CD (2004) Schizophrenia and theory of mind. Psychol Med 34:385-389

17. Corcoran R, Mercer G, Frith CD (1995) Schizophrenia, symptomatology and social inference: Investigating "theory of mind" in people with schizophrenia. Schizophr Res 17:5-13

18. Bozikas VP, Giannakou M, Kosmidis MH, Kargopoulos P, Kioseoglou G, Liolios D, Garyfallos G (2011) Insights into theory of mind in schizophrenia: the impact of cognitive impairment. Schizophr Res 130(1-3):130-136. doi:10.1016/j. schres.2011.04.025

19. Couture SM, Penn DL, Losh M, Adolphs R, Hurley R, Piven J (2010) Comparison of social cognitive functioning in schizophrenia and high functioning autism: more convergence than divergence. Psychol Med 40 (4):569-579

20. Kern RS, Green MF, Fiske AP, Kee KS, Lee J, Sergi MJ, Horan WP, Subotnik KL, Sugar C, Nuechterlein KH (2009) Theory of mind deficits for processing counterfactual information in persons with chronic schizophrenia. Psychol Med 39:645-654 
21. Langdon R, Ward PB, Coltheart M (2010) Reasoning anomalies associated with delusions in schizophrenia. Schizophr Bull 36(2):321-330. doi:10.1093/schbul/sbn069

22. Chung YS, Barch DM (2011) The effect of emotional context on facial emotion ratings in schizophrenia. Schizophr Res 131(13):235-241. doi:10.1016/j.schres.2011.05.028

23. Csukly G, Polgar P, Tombor L, Rethelyi J, Keri S (2011) Are patients with schizophrenia rational maximizers? Evidence from an ultimatum game study. Psychiatry Res 187(1-2):11-17. doi:10.1016/j.psychres.2010.10.005

24. Diaz MT, He G, Gadde S, Bellion C, Belger A, Voyvodic JT, McCarthy G (2011) The influence of emotional distraction on verbal working memory: an fMRI investigation comparing individuals with schizophrenia and healthy adults. J Psychiatr Res 45(9):1184-1193. doi:10.1016/j.jpsychires.2011.02.008

25. Addington J, Girard TA, Christensen BK, Addington D (2010) Social cognition mediates illness-related and cognitive influences on social function in patients with schizophrenia-spectrum disorders. J Psychiatry Neurosci 35(1):49-54. doi:10.1503/ Jpn.080039

26. Shean G, Bell E, Cameron CD (2007) Recognition of nonverbal affect and schizotypy. J Psychol 141(3):281-291. doi:10.3200/ Jrlp.141.3.281-292

27. Roddy S, Tiedt L, Kelleher I, Clarke M, Murphy J, Rawdon C, Roche R, Calkins M, Richard J, Kohler C, Cannon M (2012) Facial emotion recognition in adolescents with psychotic-like experiences: a school-based sample from the general population. Psychol Med 42(10):2157-2166

28. Abbott G, Green M (2013) Facial affect recognition and schizotypal personality characteristics. Early Interv Psychiatry 7 (1):58-63

29. Polanczyk G, Moffitt TE, Arseneault L, Cannon M, Ambler A, Keefe RSE, Houts R, Odgers CL, Caspi A (2010) Etiological and clinical features of childhood psychotic symptoms: results from a birth cohort. Arch Gen Psychiatry 67(4):328-338

30. Thompson A, Sullivan S, Heron J, Thomas K, Zammit S, Horwood J, Gunnell D, Hollis C, Lewis G, Wolke D, Harrison G (2011) Childhood facial emotion recognition and psychosislike symptoms in a nonclinical population at 12 years of age: results from the ALSPAC birth cohort. Cognit Neuro Psychiatry 16(2):136-157

31. Bentall RP, Kinderman P, Kaney S (1994) The self, attributional processes and abnormal beliefs-towards a model of persecutory delusions. Behav Res Ther 32(3):331-341. doi:10.1016/0005-7967(94)90131-7

32. Donohoe G, Spoletini I, McGlade N, Behan C, Hayden J, O’Donoghue T, Peel R, Haq F, Walker C, O'Callaghan E, Spalletta G, Gill M, Corvin A (2008) Are relational style and neuropsychological performance predictors of social attributions in chronic schizophrenia? Psychiatry Res 161(1):19-27. doi:10.1016/j.psychres.2007.10.001

33. Frenkel E, Kugelmass S, Nathan M, Ingraham LJ (1995) Locus of control and mental health in adolescence and adulthood. Schizophr Bull 21(2):219-226

34. Frith U, Frith CD (2003) Development and neurophysiology of mentalising. Phil Trans R Soc Lond B 358 459-473

35. Boyd A, Golding J, Macleod J, Lawlor DA, Fraser A, Henderson J, Molloy L, Ness A, Ring S, Davey Smith G (2012) Cohort profile: the 'Children of the 90s'-the index offspring of the Avon Longitudinal Study of Parents and Children. Int J Epidemiol 16:1-17

36. Golding J, Pembrey M, Jones R (2001) ALSPAC-the avon longitudinal study of parents and children. I Study methodology. Paediatr Perinat Epidemiol 15(1):74-87

37. Horwood J, Salvi G, Thomas K, Duffy L, Gunnell D, Hollis C, Lewis G, Menezes P, Thompson A, Wolke D, Zammit S,
Harrison G (2008) IQ and non-clinical psychotic symptoms in 12-year-olds: results from the ALSPAC birth cohort. Br J Psychiatry 193:185-191

38. Wing JK, Babor T, Brugha T, Burke J, Cooper JE, Giel R, Jablenski A, Regier D, Sartorius N (1990) SCAN: Schedules for clinical assessment in neuropsychiatry. Arch Gen Psychiatry 47:589-593

39. Landis JR, Koch GG (1977) Measurement of observer agreement for categorical data. Biometrics 33(1):159-174. doi: $10.2307 / 2529310$

40. Angold A, Costello EJ, Messer SC, Pickles A, Winder F, Silver D (1995) The development of a short questionnaire for use in epidemiological studies of depression in children and adolescents. Int J Methods Psychiatr Res 5:1-12

41. Sharp C, Goodyer IM, Croudace TJ (2006) The Short Mood and Feelings Questionnaire (SMFQ): A unidimensional item response theory and categorical data factor analysis of self-report ratings from a community sample of 7-through 11-year-old children. J Abnorm Child Psych 34(3):379-391. doi:10.1007/s10802-006-9027-x

42. Thapar A, McGuffin P (1998) Validity of the shortened Mood and Feelings Questionnaire in a community sample of children and adolescents: a preliminary research note. Psychiatry Res 81(2):259-268

43. Copeland WE, Shanahan L, Costello EJ, Angold A (2009) Childhood and Adolescent Psychiatric Disorders as Predictors of Young Adult Disorders. Arch Gen Psychiatry 66(7):764-772

44. Nowicki S (1976) Factor structure of locus of control in children. J Genet Psychol 129(1):13-17

45. Skuse DH, Mandy WP, Scourfield J (2005) Measuring autistic traits: heritability, reliability and validity of the Social and Communication Disorders Checklist 2. Br J Psychiatry 187:568-572

46. Nowicki S, Duke MP (1994) Individual differences in the non verbal communication of affect : the diagnosis analysis of nonverbal accuracy scale. J Nonverbal Behav 18:9-35

47. Boraston $Z$ (2001) Emotion recognition from social movement. University College London, Library of University College London

48. Wechsler D, Golombok S, Rust J (1992) Wechsler intelligence scale for children. The Psychological Corporation, San Antonio, Texas

49. Steer CD, Golding J, Bolton PF (2010) Traits contributing to the autistic spectrum. PLoS One 5 (9):e12633

50. Harell FE (2001) Regression modelling strategies: with applications to linear models, logistic regression and survival analysis. Springer, New York

51. van Buuren S, Boshuizen HC, Knook DL (1999) Multiple imputation of missing blood pressure covariates in survival analysis. Stat Med 18:681-694

52. StataCorp LPR (2009) Stata Statistical Software. College Station TX

53. Team. RC (2012) R: A language and environment for statistical computing. http://www.R-project.org/. 2012

54. Rasbash J, Steele F, Browne WJ, Goldstein H (2012) A User's Guide to MLwiN, v2.26. Centre for Multilevel Modelling, University of Bristol

55. Amemiya T (1981) Quantitative response models: a survey. J Econ Lit 19:1483-1586

56. Fraser A, Macdonald-Wallis C, Tilling K, Boyd A, Golding J, Smith GD, Henderson J, Macleod J, Molloy L, Ness A, Ring S, Nelson SM, Lawlor DA (2013) Cohort profile: the Avon Longitudinal Study of Parents and Children: ALSPAC mothers cohort. Int J Epidemiol 42(1):97-110. doi:10.1093/Ije/Dys066 
57. Button KS, Ioannidis JPA, Mokrysz C, Nosek BA, Flint J, Robinson ESJ, Munafo MR (2013) Power failure: why small sample size undermines the reliability of neuroscience. Nat Rev Neurosci 14(5):365-376. doi:10.1038/Nrn3475

58. Frith CD, Corcoran R (1996) Exploring "theory of mind" in people with schizophrenia. Psychol Med 26:521-530

59. Murray RM, Lewis SW (1987) Is schizophrenia a neurodevelopmental disorder? Br Med J 295:681-682

60. Stochl J, Khandaker GM, Lewis G, Perez J, Goodyer I, Zammit S, Sullivan S, Croudace T, Jones PB (2014) Mood, anxiety and psychotic phenomena measure a common psychopathological factor. Psychol Med. doi:10.1017/S003329171400261X
61. Jarrett RB, Vittengl RR, Doyle K, Clark LA (2007) Changes in cognitive content during and following cognitive therapy for recurrent depression: substantial and enduring but not predictive of depressive symptoms. J Consult Clin Psychol 75:432-446

62. Domitrovich CE, Cortes RC, Greenberg MT (2007) Improving young children's social and emotional competence: a randomised trial of the preschool "PATHS" curriculum. J Prim Prev 28(2):67-91

63. Steer CD, Golding J, Bolton PF (2010) Traits contributing to the autistic spectrum. PLoS One 5(9):e12633 